\title{
Corporate Entrepreneurship: a presença das dimensões da cultura nacional na cultura comercial do Grupo Algar
}

\author{
Cíntia Rodrigues de Oliveira Medeiros ${ }^{1}$ \\ Rodrigo Miranda ${ }^{2}$ \\ Alirio Severo Nogueira Jr. ${ }^{3}$
}

\section{Resumo}

Este estudo trata do Corporate Entrepreneurship, expressão que se refere às empresas capazes de estimular a iniciativa de seus funcionários, de forma que eles proponham novas ideias, novos negócios ou serviços e novos processos. A cultura organizacional, definida pelo caráter coletivo e pelos elementos que a constituem, é um fenômeno sujeito a influências sócio-culturais e históricas, o que implica considerar a existência de um componente nacional. Este trabalho analisou a Cultura Comercial do Grupo Algar à luz do conceito de Corporate Entrepreneurship, com o objetivo de identificar a presença das dimensões da cultura nacional. Utilizou-se da pesquisa documental, com a análise de documentos, impressos e eletrônicos, publicados com a finalidade de disseminar o conceito de Cultura Comercial. Os resultados apontam para uma convergência entre os conceitos de Cultura Comercial e Cultura Empreendedora; entretanto, isso não ocorre no que diz respeito às dimensões da cultura nacional.

Palavras-chave: Cultura organizacional. Intraempreendedorismo. Inovação.

\section{Introdução}

Inovação, empreendedorismo e cultura organizacional são temas recorrentes no contexto das companhias que buscam obter, manter ou ampliar seu espaço em um mercado cujas mudanças rápidas exigem respostas ime-

\footnotetext{
${ }^{1}$ Mestre em Administração pela Universidade Federal de Uberlância. Doutorado em Administração de Empresas - FGV. Professora da área de Organizações e Recursos Humanos da Universidade Federal de Uberlândia. Endereço: Av. João Naves de Avila, Campus Santa Mônica, Bloco F. Uberlândia, MG. CEP 38400-000. E-mail: cintia@fagen.ufu.br.

${ }^{2}$ Mestre em Administração. Doutorado em Administração de Empresas-FGV. Professor da área de Organizações e Recursos Humanos da Universidade Federal de Uberlândia. Endereço: Av. João Naves de Avila, Campus Santa Mônica, Bloco F, Uberlândia, MG. CEP 38400-000. E-mail: rodmiranda@netsite.com.br.

${ }^{3}$ Mestre em Administração pela Universidade Federal Rural do Rio de Janeiro. Coordenador do curso de Administração da UNIESSA - Faculdade de Marketing e Negócios. Endereço: Av das Américas, 505, Uberlândia, MG. E-mail: jacarenog@yahoo.com.br. Artigo recebido em: 21/08/2008. Aceito em: 03/04/2009. Membro do Corpo Editorial Científico responsável pelo processo editorial: Gilberto de Oliveira Moritz.
} 
diatas. A ação local e isolada não mais garante a inserção competitiva das empresas em um mercado global (CASTELLS, 2000), em que a informática $e$ as telecomunicações são capazes de gerar e disseminar informações em grandes volumes e com alta velocidade.

Nesse contexto, a capacidade de inspirar pessoas a trabalharem de maneira compartilhada e com a atenção dirigida para as tendências sinalizadas por esse conjunto de mudanças não só é relevante, como também necessária para uma companhia ser ou tornar-se competitiva. Crescimento, lealdade de clientes, qualidade, logística, criação de valor, fortalecimento da imagem, excelência operacional, ética, responsabilidade social e ambiental: são as palavras de ordem para o enfrentamento de tantos desafios.

Dessa forma, no atual cenário, o desenvolvimento do Corporate Entrepreneurship ganha importância, pois é necessário que as companhias sejam capazes de criar, continuamente, vantagens temporárias, já que a sustentação de vantagens duradouras é cada vez mais difícil, em face da conectividade presente na dinâmica da competitividade.

Este trabalho insere-se no âmbito da abordagem qualitativa e analisa a Cultura Comercial do Grupo Algar à luz do conceito de Corporate Entrepreneurship, com o objetivo de identificar a presença das dimensões da cultura nacional na cultura organizacional; as narrativas do Grupo são seu foco e, sustentando-se em uma abordagem interpretativo-simbólica (HATCH, 1993), analisa o material institucional utilizado para construir o significado de Cultura Comercial.

Inicialmente são discutidos os conceitos associados ao Corporate Entrepreneurship e suas dimensões de análise. Em seguida, enfatizam-se estudos sobre a cultura organizacional e as dimensões da cultura nacional. Posteriormente os procedimentos metodológicos são apresentados e, na sequência, a análise dos dados busca evidências que possam atender o objetivo proposto. Por fim, tecem-se as considerações finais do estudo.

\section{Corporate Entrepreneurship: conceitos e dimensões de análise}

Fillion (1999) atribui a origem dos estudos sobre empreendedorismo a Cantillon e Jean Baptiste Say, que definiam como empreendedores as pessoas que assumiam riscos em busca de lucros, aproveitando-se de oportuni- 
dades. Todavia, foi Schumpeter (1947) quem fomentou as discussões acerca do campo, associando o termo à capacidade de inovação $e$, consequentemente, ao desenvolvimento econômico.

De acordo com Schumpeter (1947), os mecanismos da mudança econômica na sociedade capitalista centram-se sobre a atividade empreendedora. Para o autor, o empreendedor e sua função são facilmente conceituados, pois trata-se, simplesmente, de fazer novas coisas ou fazer as coisas que já são feitas de um novo modo. A explicação de Schumpeter (1947), ainda que simples, ao invés de reduzir o conceito, o torna mais abrangente, já que não contempla qualquer limitação de tempo, espaço ou natureza das coisas. Assim, empreendedor é definido não só por aquele que cria novos negócios, mas, também, por aquele que é capaz de destruir a ordem econômica existente, introduzindo produtos ou serviços, por meio da criação de novas formas de organização ou, ainda, explorando os recursos então disponíveis.

O termo Corporate Entrepreneurship é referenciado na literatura com diversas outras denominações: empreendedorismo intracorporativo, intrapreneurship (intraempreendedorismo) (PINCHOT, 1987), corporate venturing (Von HIPPEL, 1977; CHESBROUGH, 2002). Em síntese, o termo diz respeito às empresas capazes de estimular a iniciativa de seus funcionários de tal forma que esses proponham novas ideias, novos negócios ou serviços e novos processos. Para Morse (1986), a definição de intrapreneur como um empreendedor que opera dentro de uma grande companhia, e não em seu próprio negócio, é questionável em função das estruturas burocráticas das grandes companhias que, segundo o autor, são incapazes de prover as recompensas e a autonomia pessoal requeridas pelo empreendedor. A despeito dessas considerações, Doh e Pearce II (2004) argumentam que o termo é aplicável a iniciativas internas, independente do tamanho ou idade da companhia.

Atividades geradoras de novos negócios através de empreendimentos externos ou internos (intrapreneur) definem empreendedorismo corporativo de forma mais abrangente. Nesse sentido, o principal desafio do Corporate Entrepreneurship é criar ou desenvolver o espírito empreendedor, e gerar uma atmosfera de inovação dentro das fronteiras das organizações (DRUCKER, 2005; DOH; PEARCE II, 2004), capaz de explorar as descontinuidades geradas pelas incertezas e mudanças próprias do ambiente no qual as organizações estão inseridas

A aproximação entre inovação, empreendedorismo e cultura organizacional é uma tendência entre os autores da área, mesmo que por 
meio de diferentes abordagens. Peters e Waterman (1986), por exemplo, atribuem à cultura organizacional a capacidade de a empresa inovar; já na perspectiva da RBV (Resource Based View), ela é vista como um recurso para a obtenção de vantagem competitiva (BARNEY, 1986). Uma cultura empreendedora (FARRELL, 1993) promove entre seus membros uma contínua busca pelo novo, seja um processo, um produto ou um serviço, caracterizando uma conduta dirigida para a obtenção de uma vantagem competitiva. Nelson e Winter (1982) definem capabilities como um padrão de atividades regulares e predizíveis, formado por várias ações coordenadas colocadas em prática antes que um problema específico ocorra, o que caracteriza a cultura de uma organização.

A estreita relação entre Corporate Entrepreneurship e o processo de inovação foi evidenciada em vários estudos (SHAW; O'LOUGHLIN; McFADZEAN, 2005) que confirmam sua definição como o esforço de promover a inovação em um ambiente incerto, sinalizando para os benefícios organizacionais que podem ser alcançados na gestão dos processos de inovação. A cultura empreendedora define-se, então, pela sua capacidade de inovar constantemente (JASSAWALLA; SASHITTAL, 2002). A literatura sobre inovação apresenta diversas conotações para o termo: tanto pode referirse aos resultados obtidos de um processo inovador ou ao próprio processo (DRUCKER, 2005). Inovar implica, essencialmente, em novidade, seja relacionada a novos produtos, novos processos, novos métodos, novos serviços, novos mercados, novas fontes de suprimentos e, até mesmo, novas formas de organizar (OJASALO, 2008; SHAW; O'LOUGHLIN; McFADZEAN, 2005).

Uma cultura inovadora é definida por Claver et al. (1998), no que é compartilhado por Hamel (2003) e Khazanchi, Lewis, Boyer (2007), como um modo de pensar e de comportar que cria, desenvolve e estabelece valores e atitudes dentro de uma companhia. Esse modo pode gerar, aceitar $e$ sustentar ideias e mudanças que resultem na eficiência da companhia, ainda que essas mudanças possam significar um conflito com o comportamento tradicional. Para Claver et al. (1998), a cultura inovadora ou empreendedora requer quatro atitudes básicas: (a) disposição da alta administração em assumir riscos; (b) a participação de todos os membros da companhia; (c) estímulo à criatividade; e (d) responsabilidade compartilhada. Em estudo semelhante, Martins e Terblanche (2003) identificam os elementos da cultura organizacional que são determinantes para sustentar a inovação e a criatividade: (1) estratégia; (2) estrutura; (3) mecanismos de suporte; (4) comportamento que encoraja a inovação; e (5) comunicação. 
A cultura organizacional, definida pelo caráter coletivo e pelos elementos que a constituem, é um fenômeno sujeito a influências socioculturais e históricas. Hofstede (1993) caracteriza-a como um fenômeno coletivo, parcialmente compartilhado entre os membros de um grupo que vive ou viveram no mesmo ambiente social onde ela foi aprendida, e não herdada. Nesse sentido, Hofstede (1984) considera a existência de camadas culturais, como a cultura nacional, que o indivíduo carrega consigo e que influencia o seu comportamento.

Hofstede (1984), ao argumentar que a cultura nacional influencia a cultura organizacional, apresenta três razões: a) as nações são historicamente originadas de unidades políticas com suas próprias instituições e sistemas legal, educacional e mercado de trabalho; b) organizações informais são usualmente baseadas em culturas; e c) fatores psicológicos e o modo de pensar dos indivíduos são parcialmente influenciados por fatores culturais nacionais formados pelas relações familiares e sistemas educacionais que diferem entre os países. Dessa forma, as dimensões que definem a cultura de um país ou região podem influenciar a cultura da organização de modo a caracterizála como empreendedora ou não.

\section{As Dimensões da Cultura Nacional e sua Influência na Cultura Empreendedora}

O estudo pioneiro de Hofstede (1984) sobre as dimensões da cultura nacional, realizado entre o final da década de 1960 e início da década de 1970, é um dos mais relevantes da área e serviu de inspiração para muitos pesquisadores (LINDELL; ARVONEN, 1997). Essa pesquisa, realizada com funcionários da IBM localizados em 40 países de todo o mundo, buscou compreender como as culturas diferem de uma região para outra. Ao examinar os dados dos questionários respondidos na pesquisa, Hofstede (1984) identificou que a maioria das diferenças entre as culturas nacionais são caracterizadas por quatro dimensões: distância do poder, individualismo, masculinidade e aversão à incerteza. Posteriormente, outro pesquisador, Bond, segundo Hofstede (1993), investigou outras culturas e identificou uma quinta dimensão, a orientação de curto prazo versus a de longo prazo, que o autor adicionou a seu modelo.

A influência de um componente nacional na liderança foi identificada por Hofstede et al. (2002) quando pesquisaram a relação entre objetivos 
empresariais e a cultura. A pesquisa foi realizada com estudantes de 15 países, que responderam questões sobre o grau de importância atribuída aos objetivos empresariais e, posteriormente, os resultados do estudo foram relacionados com as dimensões culturais. Na mesma direção pesquisas realizadas evidenciaram essa influência nos estilos de liderança (LINDELL; ARVONEN, 1997; EKVALL; ARVONEN, 1991); na orientação empreendedora da sociedade (LEE; PETERSON, 2000); e na percepção quanto à responsabilidade social empresarial (BIGNÉ et al., 2005). Já Mearns e Yule (2008) não encontraram a mesma influência no comportamento dos funcionários quanto à propensão em assumir riscos no trabalho.

A primeira das dimensões, a distância do poder, é definida por Hofstede (1984; 1993) como o grau de desigualdade, que a população de um país considera aceitável, entre dois extremos: de alta distância do poder, o que caracteriza uma sociedade muito desigual; a uma baixa distância, o que significa uma igualdade relativa. Em países com alta distância do poder, os subordinados esperam que lhes digam o que fazer, ao contrário de países com pouca distância, cujos subordinados esperam ser ouvidos.

A dimensão individualismo diz respeito ao grau de preferência que a sociedade de um país tem sobre agir de forma individual (o trabalho prevalece sobre os relacionamentos) ou como membros de grupos (relacionamentos prevalecem sobre o trabalho). Hofstede (1984; 1993) considera o coletivismo como o extremo oposto que caracteriza sociedades que dão importância ao fortalecimento de laços mais profundos entre os indivíduos e, além disso, respeitam o grupo ao qual pertencem, como, por exemplo, a família.

A terceira dimensão, masculinidade, cujo polo oposto é a feminilidade, retrata o grau que os valores associados ao papel dos homens, como assertividade, performance, sucesso e competição, prevalecem na sociedade de um país, em detrimento aos valores associados às mulheres, como qualidade de vida, relações interpessoais, defesa dos mais fracos, preocupação com o próximo, solidariedade, entre outros. Segundo Hofstede (1993), o papel das mulheres é diferente do papel dos homens em todos os países, mas em sociedades resistentes as diferenças são bem maiores que em outras.

A dimensão aversão à incerteza pode ser definida, segundo Hofstede (1993), como o grau de preferência em relação à estruturação das situações, ou seja, a ênfase que a sociedade direciona às regras claras, mesmo que não sejam escritas. Segundo o autor, uma sociedade com alto grau de aversão à incerteza entende que o que é diferente, ou novo, é perigoso; enquanto que as sociedades com baixa aversão à incerteza têm curiosidade por aquilo que é diferente. 
Quanto à orientação de longo prazo versus de curto prazo, Hofstede (1993) define que o longo prazo está associado a valores orientados em direção ao futuro, como a persistência; já o curto prazo está orientado em direção ao passado e presente, como a tradição e as obrigações sociais. $\mathrm{O}$ autor defende que as dimensões culturais são ferramentas para analisar o modo como a sociedade funciona e, inclusive, o modo de gestão dos negócios daquela sociedade.

A subsidiária brasileira da IBM também participou da pesquisa de Hofstede (1981) que, ao ser reaplicada quase três décadas depois por Tanure (2005), no Brasil e em países da América Latina, obteve resultados diferentes (Quadro 1):

As diferenças encontradas nas duas pesquisas são justificadas por Tanure (2005) como decorrentes das mudanças que ocorreram entre as quase três décadas que as separam: o acesso à informação $e$ à instrução, o avanço tecnológico acelerado e as próprias transformações nas estruturas ocorridas no âmbito das organizações, para ressaltar algumas, contribuíram para mudanças significativas nessas dimensões.

\begin{tabular}{|l|c|c|cc|}
\hline \multicolumn{1}{|c|}{ Dimensões culturais } & Grau & Tanure & \multicolumn{2}{c|}{ Grau Hofstede } \\
\hline Aversão à incerteza & Baixa & 36 & Alta & 76 \\
\hline Masculinidade & Alta & 55 & Baixa & 49 \\
\hline Individualismo & Baixa & 41 & Baixa & 38 \\
\hline Distância do poder & Alta & 75 & Alta & 69 \\
\hline Perspectiva de longo prazo & Alta & 63 & Alta & 65 \\
\hline
\end{tabular}

Quadro 1: Caracterização do Brasil sobre as dimensões culturais nacionais segundo Hofstede. Fonte: Hofstede (2007) e Tanure (2005).

\section{Modelo de Análise: o ranking de empreendedorismo corporativo do IBIE}

O ranking de empreendedorismo corporativo, criado pelo Instituto Brasileiro de Intraempreendedorismo (IBIE) e publicado pela Revista Exame, é resultado de uma pesquisa realizada com as empresas inscritas, e tem como objetivo identificar as companhias mais bem-sucedidas em estimular seus funcionários a contribuir para o processo de inovação. A Pinchot \& Company é uma organização especializada em inovação, que tem por objetivo difundir 
o intraempreendedorismo por meio de workshops, palestras e treinamentos, tendo participado de processos e programas de inovação em empresas listadas na Revista Fortune. Os critérios usados na metodologia são os mesmos da Pinchot \& Company, que ilustram o modelo de Gestão de Empresas Empreendedoras (Quadro 2), segundo o IBIE (2008):

As empresas empreendedoras, segundo o IBIE (2008), caracterizam-se por uma estrutura organizacional preparada para identificar tendências, para promover melhorias no ambiente de trabalho e para implementar práticas de gestão propícias à inovação e criação de valor para os seus stakeholders. Este estudo utiliza o modelo de gestão de empresas empreendedoras do IBIE para estabelecer combinações com o estudo de Hofstede (1984) e de Tanure (2005) acerca das dimensões culturais nacionais, como exposto na Seção 3.

\begin{tabular}{|l|l|}
\hline Dimensão & Critério \\
\hline $\begin{array}{l}\text { Comportamento } \\
\text { da empresa }\end{array}$ & $\begin{array}{l}\text { Disseminação da visão estratégica; Treinamento } \\
\text { contínuo; Apoio à inovação pelo líder; Foco no futuro; } \\
\text { Foco no cliente; Responsabilidade ambiental, social e } \\
\text { ética; Tratamento dispensado às pequenas iniciativas. }\end{array}$ \\
\hline $\begin{array}{l}\text { Processo de } \\
\text { trabalho }\end{array}$ & $\begin{array}{l}\text { Poder de decisão dos grupos; Obtenção de permissões; } \\
\text { Tempo de recursos disponíveis; Auto seleção; Repasse } \\
\text { de responsabilidade e atribuições; Cruzando barreiras; } \\
\text { Comunidade organizacional fortalecida; Opções de } \\
\text { ajuda (caminho interno); Transparência e verdade; } \\
\text { Bom ambiente (qualidade do ambiente); Conforto } \\
\text { com as mudanças; Memória organizacional. }\end{array}$ \\
\hline $\begin{array}{l}\text { Recompensa } \\
\text { à inovação }\end{array}$ & $\begin{array}{l}\text { Tolerância a riscos, erros e fracassos; Critérios de } \\
\text { avaliação de projeto; Apoio a intraempreendedores; } \\
\text { Medição de recompensas. }\end{array}$ \\
\hline
\end{tabular}

Quadro 2: Modelo de Gestão de Empresas Empreendedoras.

Fonte: IBIE (2008).

\section{Metodologia}

O trabalho é de natureza qualitativa e situa-se no âmbito do paradigma interpretativo (MORGAN, 1980), cujas suposições baseiam-se na ideia de que a realidade social não existe em um sentido concreto, mas isso sim é produto da subjetividade e das experiências intersubjetivas dos indivíduos. As pesquisas realizadas nessa perspectiva sugerem que a realidade das orga- 
nizações emerge de estruturas simbólicas das quais os indivíduos criam significados. As organizações utilizam-se da linguagem, verbal e não-verbal, de forma ontológica e não simplesmente como ferramenta de comunicação e descritiva, definindo, assim, um modo de ser no mundo.

Este trabalho tem como foco as narrativas da empresa e, sustentandose em uma abordagem interpretativo-simbólica (HATCH, 1993), analisa o material institucional utilizado pelo Grupo para construir o significado de Cultura Comercial, e, assim, identificar a presença das dimensões da cultura nacional. A abordagem interpretativo-simbólica, segundo Hatch (1993, p. 669), "compreende a noção de símbolo como algo que representa uma associação consciente ou inconsciente com algo mais amplo, usualmente um conceito ou significado mais abstrato".

A pesquisa documental utilizou-se de documentos institucionais (impressos e eletrônicos) disponibilizados pelo Grupo, além daqueles publicados na mídia de negócios, como jornais e revistas de ampla circulação. A coleta de dados foi realizada na website da empresa e no Departamento de Relações Públicas, que forneceu parte do material institucional. Os documentos foram analisados de forma a selecionar o material para, em seguida, proceder-se à análise de conteúdo por categoria, como propõe Bardin (1979). As categorias elencadas para análise foram: (a) comportamento da empresa - visão quanto à inovação; (b) os processos de trabalho - autonomia; $e$ (c) as recompensas à inovação - aceitação do erro e risco. A análise de conteúdo objetivou identificar, em cada uma das categorias, as dimensões da cultura nacional.

A seleção do Grupo Algar deve-se, principalmente, à sua presença nas duas edições do ranking de empreendedorismo corporativo, nas quais figura entre as dez companhias mais bem-sucedidas em estimular seus funcionários a contribuir para o processo de inovação. Além disso, o Grupo Algar atua em um ramo altamente competitivo, que sofreu mudanças radicais nas últimas décadas, as telecomunicações, o que constitui em um cenário propício à análise do conceito de empreendedorismo corporativo.

\section{Discussão e Resultados}

A história do Grupo Algar, narrada nos diversos documentos institucionais, teve início em 1954, quando Alexandrino Garcia criou, na re- 
gião do Brasil Central, a Cia. de Telefones do Brasil Central - CTBC, empresa que deu origem ao Grupo Algar. Com quase 50 anos, o fundador enfrentou os desafios políticos e econômicos do Brasil e, acreditando no futuro de uma região cujo potencial ainda era desconhecido pela maioria dos empresários, começou a realizar, em 1954, um empreendimento: ligar a região do Brasil Central a todo País, por meio das telecomunicações.

Em 1961, o Conselho Nacional de Telecomunicações (CONTEL) foi criado e, em 1962, o Código Brasileiro de Telecomunicações definiu, pela primeira vez, as linhas de uma política nacional para o setor. A CTBC expandiu progressivamente seus serviços, chegando ao estado de São Paulo em 1963, passando a operar os serviços em 25 localidades do Brasil Central. Nessa década, a CTBC incorporou sucessivamente empresas telefônicas em algumas cidades mineiras e em Franca - SP, contribuindo, também, para a geração de novos empregos nessas cidades.

A Algar ampliou suas competências, passando a atuar em outras áreas de negócios. Em 2005, iniciou um processo de expansão nas áreas de telecomunicações, agronegócios, serviços de infraestrutura e turismo. No setor de telecomunicações, atualmente, são quatro empresas: (1) CTBC (telefonia fixa, celular, comunicação de dados, serviços de rede, acesso à Internet, data center e TV a cabo); (2) ACS - Call Center; (3) Engeset (serviços de engenharia); e (4) SABE (listas e guias tefônicos). A ABC Inco (processamento de soja) e $\mathrm{ABC} A \& \mathrm{P}$ (plantio de grãos) são as empresas do setor de agronegócios. $\mathrm{Na}$ área de Serviços de Infraestrutura são três empresas: (1) ABC Táxi Aéreo (compra e venda de aeronaves, táxi aéreo e manutenção de aeronaves); (2) SPACE (segurança patrimonial, eletrônica e documental); (3) COMTEC (administração de terminais urbanos e centros comerciais). A Rio Quente Resorts é a empresa pela qual o Grupo atua no setor de turismo..

A breve história do Grupo Algar revela uma trajetória marcada pela inovação, no sentido atribuído por autores (OJASALO, 2008; SHAW; O'LOUGHLIN; McFADZEAN, 2005) que discutem a concepção de inovação de forma mais ampla do que a criação de algo nunca antes inventado. Ao longo de mais de cinquenta anos, o Grupo Algar, considerando a empresa que o originou, expandiu seu mercado para além das fronteiras locais, lançou novos produtos no mercado e, especialmente, uma nova forma de organização, ou como o próprio grupo denomina, um modelo de gestão que se tornou referência nacional. 
A instalação da ACS - Call Center nos arredores da cidade de Uberlândia, em 1999, é exemplo de como o Grupo provocou mudanças na economia, nos hábitos, no sistema de transporte público de passageiros, no mercado imobiliário (valorização dos terrenos da região), meio universitário e na geração de empregos e oportunidades. A Secretaria Municipal de Transportes fez mudanças de itinerário nas linhas e exigiu que as empresas adaptassem seus veículos aos portadores de necessidades especiais. É o segundo maior empregador de Uberlândia, oferecendo oportunidades para três parcelas da população que, tradicionalmente, estão à margem do mercado de trabalho: pessoas da terceira idade, portadores de necessidades especiais $e$ aqueles que buscam o primeiro emprego. A ACS causou impacto no setor educacional da cidade que, de seis instituições de ensino superior em 1999, passou para 11, o que consolida a cidade como um dos polos importantes de ensino superior do país.

Dessa forma, o Grupo Algar, ao evidenciar os impactos causados pela instalação de um "novo negócio", mostra-se capaz de, nos termos de Schumpeter (1947), introduzir uma perturbação econômica na região em que atua, já que a criação da ACS provocou a entrada de novos serviços, produtos e, ainda, mudanças econômicas, sociais, culturais, governamentais $e$ tecnológicas.

Um trecho nos documentos institucionais do Grupo, evidencia o pioneirismo como uma característica que lhe é atribuída: "O pioneirismo e a oferta de tecnologia avançada são características do Grupo Algar nos seus mais de 50 anos de atuação", e atribui como causa direta o estilo de gestão: "O investimento constante em treinamento de seus colaboradores, aliado à experiência operacional, além de constantes avaliações, pesquisas de mercado e revisão de seus processos, permitem que ano após ano a Algar possa inovar, agregando diferenciações e desenvolvendo novas linhas de produtos e serviços". E é esse estilo de gestão que lhe fornece os atributos de inovar continuamente (JASSAWALLA; SASHITTAL, 2002), identificando-se como uma cultura empreendedora.

Para reforçar a imagem de uma cultura de pioneirismo, ou empreendedora, o Grupo ressalta alguns exemplos (Quadro3): 


\begin{tabular}{|l|l|}
\hline Corporativo & $\begin{array}{l}\text { a. Primeira empresa no Brasil a utilizar a expressão Talentos Humanos, como } \\
\text { uma filosofia na gestão de pessoas. } \\
\text { b. Primeira empresa a utilizar avaliação de performance - todos os talentos } \\
\text { avaliam uns aos outros. } \\
\text { c. Uma das primeiras empresas familiares no Brasil a instituir um Conselho de } \\
\text { Família. }\end{array}$ \\
\hline Telecomunicações & $\begin{array}{l}\text { a. Primeira a implantar a telefonia celular no interior do País. } \\
\text { b. Primeira a trazer a telefonia digital, a telefonia celular pré-paga, a lançar o } \\
\text { telefone pré-pago fixo, a telefonia via cabo, o fax celular, o reconhecimento de } \\
\text { fala e o telefone público para deficientes físicos de voz e audição. } \\
\text { c. Primeira empresa no Brasil a implantar serviços de Contact Center em } \\
\text { estrutura específica para a atividade }\end{array}$ \\
\hline Agronegócio & $\begin{array}{l}\text { a. A primeira empresa de seu segmento no Brasil a alcançar a certificação } \\
\text { conjunta ISO 9002 e 14001. } \\
\text { b. Pioneira no processamento de soja no cerrado. Com a entrada em operação } \\
\text { da nova planta no Maranhão em 2007, foi a primeira esmagadora de soja do } \\
\text { Estado e a primeira a implantar uma unidade de processamento de soja no } \\
\text { interior da região Nordeste. }\end{array}$ \\
\hline Turismo & $\begin{array}{l}\text { a. O Rio Quente Resorts foi o primeiro a utilizar cartão eletrônico de consumo } \\
\text { interno pelos clientes, oferecendo maior praticidade e conforto aos hóspedes. } \\
\text { b. Maior parque aquático de águas termais e com atrações inéditas no Brasil. } \\
\text { c. Primeiro hotel no Estado de Goiás a conquistar a certificação ISO 14001. }\end{array}$ \\
\hline Infraestrutura & $\begin{array}{l}\text { a. Primeira empresa a prestar serviço de rastreamento veicular no Estado de } \\
\text { Minas Gerais. } \\
\text { b. Primeira empresa na região do Triângulo Mineiro a prestar serviço de } \\
\text { monitoramento de imagem à distância em vias públicas. }\end{array}$ \\
\hline Quadro3: Exemplome
\end{tabular}

Quadro 3: Exemplos de pioneirismo do Grupo e das empresas que o compõem.

Fonte: Documentos da pesquisa.

\section{A Presença das Dimensões da Cultura Nacional na Cultura Comercial do Grupo Algar}

A combinação proposta por Lindell e Arvonen (1997) e o estudo de Mearns e Yule (2008) serviram de inspiração para estabelecer as combinações entre as dimensões da cultura nacional (HOFSTEDE, 1984) e da cultura empreendedora (IBIE, 2008) que serão consideradas como modelo de análise (Quadro 4) do presente estudo.

O que o Grupo denomina de Cultura Comercial é o conjunto de ações mercadológicas que tem como lema entender antes de atender, o que permite compartilhar, e não responder a uma necessidade. A base da Cultura Comercial é o foco do cliente. Dessa forma, a ênfase da administração é comercial: todos os funcionários desempenham a função de vendedores, res- 
ponsáveis, ainda, pelo acompanhamento e pela entrega do produto ou serviço. O funcionário assume múltiplas responsabilidades para garantir a qualidade no atendimento ao cliente. Com isso, a área de relações mercadológicas representada no Grupo busca a retomada de valores, usando a comunicação como ferramenta estratégica de marketing.

A implementação da Cultura Comercial no Grupo ficou a cargo do Comitê de Desenvolvimento da Cultura Comercial e da Unialgar, que têm a

\begin{tabular}{|c|c|c|c|c|}
\hline \multicolumn{2}{|c|}{ Dimensões da cultura } & \multicolumn{3}{|c|}{ Pilares da cultura corporativa } \\
\hline & & $\begin{array}{c}\text { Comportamento } \\
\text { da empresa }\end{array}$ & $\begin{array}{c}\text { Processo de } \\
\text { trabalho }\end{array}$ & $\begin{array}{c}\text { Recompensa à } \\
\text { Inovação }\end{array}$ \\
\hline \multirow[t]{2}{*}{$\begin{array}{l}\text { Distância do } \\
\text { poder }\end{array}$} & Alta & $\begin{array}{c}\text { Transmite } \\
\text { informações }\end{array}$ & Muito estruturado & Sem critérios \\
\hline & Baixa & $\begin{array}{c}\text { Construída } \\
\text { socialmente } \\
\text { Transparência e } \\
\text { verdade }\end{array}$ & $\begin{array}{l}\text { Comunidade } \\
\text { organizacional } \\
\text { fortalecida }\end{array}$ & $\begin{array}{l}\text { Critérios são } \\
\text { claros }\end{array}$ \\
\hline \multirow[t]{2}{*}{$\begin{array}{l}\text { Masculinidade } \\
x \text { feminilidade }\end{array}$} & Masculina & Ambiente neutro & $\begin{array}{c}\text { Centralizado no } \\
\text { líder }\end{array}$ & $\begin{array}{l}\text { Não reconhece } \\
\text { intraempreendedores }\end{array}$ \\
\hline & Feminina & $\begin{array}{l}\text { Alta qualidade de } \\
\text { vida no trabalho }\end{array}$ & $\begin{array}{l}\text { Poder de decisão } \\
\text { dos grupos }\end{array}$ & $\begin{array}{l}\text { Apoio aos intra- } \\
\text { empreendedores }\end{array}$ \\
\hline \multirow[t]{2}{*}{ Individualismo } & Individualismo & Diretivo & $\begin{array}{l}\text { Necessita obten- } \\
\text { ção de permissão }\end{array}$ & Competição \\
\hline & Coletivismo & $\begin{array}{l}\text { Considera } \\
\text { pequenas } \\
\text { iniciativas }\end{array}$ & $\begin{array}{c}\text { Repasse de } \\
\text { responsabilidades } \\
\text { e atribuições }\end{array}$ & $\begin{array}{l}\text { Colaboração } \\
\text { entre equipes }\end{array}$ \\
\hline \multirow[t]{2}{*}{$\begin{array}{l}\text { Aversão à } \\
\text { incerteza }\end{array}$} & Alta & $\begin{array}{c}\text { Tarefas } \\
\text { especializadas }\end{array}$ & $\begin{array}{l}\text { Resistente a } \\
\text { mudanças }\end{array}$ & $\begin{array}{l}\text { Erros e fracassos } \\
\text { são punidos }\end{array}$ \\
\hline & Baixa & $\begin{array}{c}\text { Treinamento e } \\
\text { desenvolvimento } \\
\text { contínuo }\end{array}$ & $\begin{array}{c}\text { Conforto com as } \\
\text { mudanças }\end{array}$ & $\begin{array}{l}\text { Erros e fracassos } \\
=\text { base aprendi- } \\
\text { zagem }\end{array}$ \\
\hline \multirow[t]{2}{*}{$\begin{array}{l}\text { Orientação } \\
\text { quanto ao } \\
\text { prazo }\end{array}$} & Longo prazo & $\begin{array}{c}\text { Foco nos } \\
\text { stakeholders } \\
\text { Responsabilidade } \\
\text { social e ambiental }\end{array}$ & $\begin{array}{l}\text { Foco no planeja- } \\
\text { mento }\end{array}$ & $\begin{array}{l}\text { Recompensas } \\
\text { sociais }\end{array}$ \\
\hline & Curto prazo & Foco no acionista & $\begin{array}{l}\text { Foco em } \\
\text { resultados }\end{array}$ & $\begin{array}{l}\text { Recompensas } \\
\text { materiais }\end{array}$ \\
\hline
\end{tabular}

Quadro 4: Dimensões da cultura x pilares da cultura corporativa.

Fonte: Adaptado pelos autores a partir de Hofstede (1991) e IBIE (2008). 
incumbência de implementar as ações que impulsionem as atividades comerciais em todas as empresas do Grupo. As atividades são desenvolvidas sustentando-se nos pilares da Cultura Comercial: 1) Valorização e respeito ao cliente; 2) Associado como vendedor; 3) Ética no relacionamento com o mercado; 4) Ferramentas de marketing; 5) Eficácia nos processos de atendimento ao cliente; 6) Ousadia com lucratividade; e 7) Celebrar as conquistas.

As atividades educacionais desenvolvidas na Unialgar visam sensibilizar e mobilizar os associados para uma atuação no foco do cliente, ao mesmo tempo em que oferece instrumentos que a viabilizam. A finalidade de conduzir uma série de ações de desenvolvimento e sensibilização é que todos os associados entendam o significado do cliente para os negócios, de um modo geral, e para o grupo Algar, especialmente.

Para alcançar o objetivo proposto neste estudo, a análise será orientada pela comparação entre os pilares da cultura empreendedora combinados com as dimensões da cultura nacional (Quadro 5) e a caracterização da Cultura Comercial do Grupo Algar, sendo que a cultura do Grupo está disseminada em documentos institucionais.

A cultura empreendedora definida pelo IBIE (2008), quando comparada às dimensões da cultura nacional (HOFSTEDE, 1991), caracteriza-se pela baixa distância do poder, pela feminilidade, pelo coletivismo, pela baixa aversão à incerteza e por uma orientação pelo longo prazo. O material institucional analisado evidencia que a Cultura Comercial do Grupo Algar caracteriza-se, quanto aos pilares da cultura empreendedora, da forma apontada nos seguintes subitens.

\subsection{Comportamento da Empresa}

O Grupo incentiva a participação do funcionário nas decisões de suas áreas e/ou empresas. Para a Algar, isso é possível pelo comprometimento com os objetivos, passando diretamente pela formação do empregado, que não se dá apenas com a promoção de cursos, mas valendo-se da democratização da informação, da gestão do conhecimento e dos fóruns de acompanhamento de experiências. Um dos canais utilizados para a democratização da informação é a TV Algar, programa jornalístico que pode ser acessado na intranet e em áreas comuns. A empresa também conta com o Toda Hora, disponibilizado no local de maior movimentação, onde são exibidas notícias sobre o Grupo, promoções de produtos e serviços direcionados para o públi- 


\begin{tabular}{|c|c|c|c|c|}
\hline \multicolumn{2}{|c|}{ Dimensões da cultura nacional } & \multicolumn{3}{|c|}{ Pilares da cultura empreendedora } \\
\cline { 3 - 5 } & $\begin{array}{c}\text { Comportamento } \\
\text { da empresa }\end{array}$ & $\begin{array}{c}\text { Processo de } \\
\text { trabalho }\end{array}$ & $\begin{array}{c}\text { Recompensa à } \\
\text { Inovação }\end{array}$ \\
\hline $\begin{array}{c}\text { Distância do } \\
\text { poder }\end{array}$ & Baixa & $\begin{array}{c}\text { Construída } \\
\text { socialmente } \\
\text { Transparência } e \\
\text { verdade }\end{array}$ & $\begin{array}{c}\text { Comunidade } \\
\text { organizacional } \\
\text { forte }\end{array}$ & $\begin{array}{c}\text { Critérios são } \\
\text { claros }\end{array}$ \\
\hline $\begin{array}{c}\text { Masculinidade } \\
\text { x feminilidade }\end{array}$ & Feminina & $\begin{array}{c}\text { Alta qualidade de } \\
\text { vida no trabalho }\end{array}$ & $\begin{array}{c}\text { Poder de decisão } \\
\text { dos grupos }\end{array}$ & Antraempreendedores \\
\hline $\begin{array}{c}\text { Individualismo } \\
\text { Coletivismo }\end{array}$ & $\begin{array}{c}\text { Considera } \\
\text { pequenas } \\
\text { iniciativas }\end{array}$ & $\begin{array}{c}\text { Repasse de } \\
\text { responsabilidades } \\
\text { e atribuições }\end{array}$ & $\begin{array}{c}\text { Colaboração } \\
\text { entre equipes }\end{array}$ \\
\hline $\begin{array}{c}\text { Aversão à } \\
\text { incerteza }\end{array}$ & Baixa & $\begin{array}{c}\text { Treinamento } e \\
\text { desenvolvimento } \\
\text { contínuo }\end{array}$ & $\begin{array}{c}\text { Conforto com as } \\
\text { mudanças }\end{array}$ & $\begin{array}{c}\text { Erros e fracassos } \\
\text { = base aprendi- } \\
\text { zagem }\end{array}$ \\
\hline $\begin{array}{c}\text { Orientação } \\
\text { quanto ao } \\
\text { prazo }\end{array}$ & Longo prazo & $\begin{array}{c}\text { Foco nos } \\
\text { stakeholders }\end{array}$ & $\begin{array}{c}\text { Foco no planeja- } \\
\text { mento }\end{array}$ & $\begin{array}{c}\text { Recompensas } \\
\text { sociais }\end{array}$ \\
\hline
\end{tabular}

Quadro 5: Dimensões da cultura nacional e pilares da cultura empreendedora.

Fonte: Adaptado pelos autores a partir de Hofstede (1991) e IBIE (2008).

co interno. O Grupo utiliza-se da Revista Algar, eletrônica e impressa, como veículo para comunicação. O periódico é uma sequencia da Revista Teleco e tem como objetivo oferecer aos clientes uma publicação moderna e com conteúdo inovador.

Os veículos de comunicação do Grupo são variados e têm larga abrangência. Porém, ressalta-se que, quanto à transparência e verdade e à construção social da cultura da empresa, os indícios são contraditórios, pois os veículos são utilizados para transmitir as informações, os aspectos simbólicos e, sobretudo, a disseminação da imagem que o Grupo faz de si mesmo. Entretanto, optou-se por classificá-los como associados à baixa distância do poder, dado o caráter interpretativo-simbólico do estudo.

Uma iniciativa pioneira, o Conselho de Clientes, tem como principal objetivo estabelecer a sistemática para um canal de comunicação entre os clientes e a direção da empresa, visando antecipar, implementar ou corrigir situações e manter contínuo o aprimoramento dos serviços prestados em todos os segmentos. A proposta é aproximar os diversos segmentos da comunidade nos quais a empresa atua por meio da valorização do diálogo com a 
sociedade e do desenvolvimento de um canal de comunicação mais eficiente, com o objetivo de facilitar a implementação de ações que aprimorem os serviços prestados pela CTBC.

O levantamento e monitoramento dos indicadores de satisfação dos clientes são feitos obtendo índices parciais e anuais. A metodologia utilizada identifica quais são os ofensores do índice de satisfação, permitindo, assim, que ações sejam realizadas para corrigi-los. Além de pesquisa de satisfação, a reestruturação da empresa, criando uma área específica para a retenção $e$ relacionamento (CRF), e o programa de relacionamento Ligação são ações dirigidas para proporcionar maior satisfação aos clientes.

Nos documentos analisados, as evidências quanto à orientação para a preservação do meio ambiente são fortes. O Grupo é proativo na adoção de medidas de preservação, obtenção de certificações e implementação de programas e ações, como a instalação de um comitê que analisa periodicamente o uso de recursos energéticos e quesitos ambientais. Em 2007, a ABC Inco iniciou a transição de matriz energética para geração de vapor, do óleo diesel BPM para a biomassa (bagaço de cana), que além de reaproveitar resíduos de processamento, resultando em uma redução considerável na emissão de poluentes na atmosfera. A CTBC trocou seus veículos por modelos mais econômicos e menos poluentes para realizar os transportes de distribuição dos produtos. No Rio Quente Resorts, a substituição dos equipamentos de alto consumo com baixa eficiência gerou grande economia.

Essas ações, dentre outras, são exemplos de que o Grupo valoriza pequenas iniciativas, e não apenas inovações de alto impacto. Esses exemplos indicam a presença da dimensão cultural coletivismo e um comportamento inovador, no sentido dado por Claver et al. (1998); Hamel (2003) e Khazanchi; Lewis; Boyer (2007).

Desde a implantação do Sistema de Gestão Ambiental (SGA), em 1999, a Inco coleta, armazena e envia para a descontaminação, lâmpadas queimadas, além de reciclar $100 \%$ do óleo lubrificante utilizado, resíduos de papelão, madeira, metal e plásticos. Para o correto descarte de baterias usadas dos equipamentos, a CTBC iniciou o processo de recolhimento delas e entrou em contato com os fabricantes para realizar os procedimentos adequados. A CTBC e o Rio Quente Resorts direcionam todas as embalagens recebidas (plástico, madeira e papelão) e outros resíduos para reciclagem ou reutilização. 
As áreas de reserva legal e preservação permanente estão em conformidade com a lei. O Rio Quente Resorts está situado em área adjacente a uma área protegida, com extensão de aproximadamente 6.000 metros quadrados. As nascentes termais e cursos d'água pertencem à União, porém a superfície pertence ao resort; e este tem uma grande preocupação com a preservação ambiental do local, bem como dos cursos d'água e nascentes.

O foco nos stakeholders e na Responsabilidade Social e Ambiental está evidenciado no material analisado, conforme exposto anteriormente. A criação do Conselho de Clientes, as ações engendradas em prol do meio ambiente, ainda que de cunho comercial, e os programas voltados para a satisfação do cliente evidenciam a orientação para o longo prazo.

A educação continuada é de responsabilidade da universidade corporativa (Unialgar), cujo modelo de gestão é referência nacional, na qual são ministrados programas de treinamento e capacitação, garantindo a aprendizagem contínua dos associados. Esse comportamento do Grupo revela a presença de baixa aversão à incerteza.

Quanto à carreira dos funcionários, o Grupo pratica a estrutura de carreira em Y, o que garante reconhecimento e ascensão para profissionais de campo, que sabem "pôr a mão na massa", mas nem sempre se dão bem em cargos gerenciais. O Grupo investe em Processo de Desenvolvimento Individualizado, o que estimula o intrapreneur, conforme Doh e Pearce II (2004): (1) da Carreira - realiza o mapeamento das competências de cada profissional, reforça os pontos fortes e indica uma série de ações para minimizar as dificuldades do executivo em termos de conhecimentos, habilidades e atitudes; (2) da Saúde - para gerar melhorias na qualidade de vida, o profissional é avaliado por uma equipe composta por médicos, treinadores físicos, nutricionistas, psicólogos e psiquiatras, que fornecem orientações gerais de como agir positivamente sobre o bem-estar pessoal e profissional.

A orientação para a carreira do funcionário não evidencia aversão à incerteza, nem mesmo caracteriza orientação forte para o planejamento. Ao contrário, o modo como o Grupo comporta-se em relação ao desenvolvimento de múltiplas competências lhe confere o caráter de flexibilidade necessária para lidar com as mudanças do ambiente no qual está inserido.

Quanto à dimensão feminina, sua presença verifica-se nos programas e ações do Grupo acerca da qualidade de vida no trabalho. Anualmente, o Grupo realiza um estudo de satisfação dos associados, reforçando a consciência de que o talento humano não é uma máquina e está sujeito aos efeitos 
das emoções. Tem um trabalho estruturado que oportuniza os associados a vivenciarem suas emoções de forma madura no ambiente profissional, e, além disso, realiza um trabalho sobre o impacto psicológico na sociedade.

Conhecida em seu universo de relacionamento, a Algar é detentora de marcas de grande valor, como CTBC, ABC Inco e Rio Quente Resorts, consolidadas no tempo, top of mind nos mercados em que atuam e reconhecidas pelos clientes aos quais servem. A expressão da empresa quanto à sua imagem é que "A percepção, por parte da opinião pública, desse conjunto de empresas, suas marcas, de seu alinhamento e da integração de sua comunicação é o que constitui o patrimônio de imagem da Algar" (ALGAR. O Grupo reforça, na Revista Algar, nos documentos institucionais, que "A marca lidera a chegada dos produtos ao mercado. As marcas corporativas do Grupo Algar são fortes aliadas no relacionamento com o consumidor/cliente, transmitindo confiança e credibilidade sob uma identidade visual".

\subsection{Processo de Trabalho}

A gestão do Grupo é regida por princípios de governança corporativa que primam por boas práticas administrativas. O Grupo expressa ter "forte política interna de planejamento em todos os níveis corporativos", "altos níveis de controle e acompanhamento de seus processos de gestão" e "transparência tanto externa como interna". A administração do Grupo utiliza o sistema de administração colegiada. O controle acionário é de total propriedade dos membros da família do fundador, porém, nos documentos analisados, evidencia-se a separação entre segmentos familiares e empresas. O foco no planejamento evidencia a orientação para o longo prazo

Os documentos analisados permitem observar que o Grupo orienta-se para criar uma comunidade organizacional fortalecida, o que está associado à baixa distância do poder: "formar no empregado a mentalidade para produzir com a cultura de 'Foco do Cliente' e participar ativamente das decisões do Grupo passa por um processo de motivação que depende da transparência na comunicação e na valorização das ideias". O Grupo valoriza seus associados, nomenclatura utilizada para funcionário, correlato de estruturas hierárquicas piramidais e da cultura de emprego.

Nos documentos analisados, o Grupo justifica que "como associado, o profissional sente-se e é considerado como um sócio do negócio, em que, apesar de não investir capital, investe inteligência e dedicação", o que pode 
ser caracterizado como o repasse de responsabilidades e atribuições, aspecto associado á dimensão coletivismo. O respeito ao ser humano, que o Grupo esclarece não se tratar de um recurso, mas "é um talento que trabalha, mas também que tem sentimentos e emoções", é o ponto-chave para obter dele a motivação e as ideias criativas que, no final, farão o diferencial dos negócios.

No processo de avaliação coletiva dos profissionais, periodicamente, são realizados encontros em que os associados expressam opiniões sobre seus superiores. A valorização do profissional começa antes mesmo da sua contratação. A aprovação de processos de admissão, assim como os de demissão, passa, obrigatoriamente, por três instâncias: o superior do aprovado, o superior do superior e a Diretoria de Talentos Humanos.

O Grupo reforça que a manutenção da política de ouvir os associados e de sua participação nas decisões, bem como a transparência com o associado, serão cada vez mais exercitadas a fim de torná-las fortes e efetivas e, sobretudo, fortalecer o relacionamento das equipes com as lideranças. Dessa forma, quanto ao processo de trabalho, as evidências encontradas nos documentos institucionais indicam que o Grupo estimula a participação na decisão em grupos, o que demonstra associação com a dimensão feminina do estudo de Hofstede (1991). Não foram encontradas evidências claras da dimensão conforto com as mudanças que permitam fazer deduções acerca da sua associação com as dimensões da cultura nacional.

\subsection{Recompensas}

O Grupo incentiva os funcionários a sugerirem melhorias nos processos, produtos e serviços das empresas por meio dos Programas de Gestão de Processos (PGP) e de Gestão de Ideias (PGI), que são implementadas. Esses programas evidenciam o apoio a intraempreendedores, o que está associado à dimensão da cultura nacional feminilidade. Anualmente, os melhores projetos são expostos na Mostra PGP e PGI. Todas as equipes, formadas por dois a sete associados, recebem bônus correspondentes a uma parte dos resultados financeiros líquidos obtidos com a implementação do projeto. $\mathrm{O}$ PGI, por sua vez, foca o processo de geração de ideias mais simples, é de rápida execução e produz impacto direto na produtividade dos empregados.

O Prêmio de Excelência Algar foi instituído para ampliar o reconhecimento da gestão das empresas controladas considerando os Fatores Críticos de Sucesso para a sustentabilidade e perenidade de seus negócios. A cada 
ano é destacada a empresa do Grupo Algar que melhor evidencia o atendimento de determinados critérios que compõem cada um dos eixos estratégicos: Foco do Cliente, Talentos, Gestão do Conhecimento e Inovação, Valores, Visão Compartilhada e Rentabilidade.

Os critérios para recompensas são claros, em todos os programas de incentivos, o que está associado à baixa distância do poder. Os incentivos são mistos; as equipes são estimuladas com recompensas materiais (bônus financeiros, participação nos resultados, etc.) e sociais (exposição dos trabalhos, reconhecimento da gestão e destaque da empresa), o que permite inferir o predomínio de uma orientação para o curto prazo, em virtude de o peso das recompensas materiais ser maior. Não foram encontradas evidências quanto à colaboração entre equipes, mas, sim, a competição, visto que a premiação, no caso do PGP, é dirigida às equipes vencedoras, no caso do PGI, ao empregado individualmente e, no Prêmio Excelência Algar, a uma empresa do grupo, o que pode estimular o espírito de competição. Quanto à forma de o Grupo lidar com erros e fracassos, não foram encontradas evidências que permitam afirmar que eles se constituam em base para a aprendizagem.

A síntese dos resultados evidencia que as dimensões da cultura nacional brasileira, conforme os estudos realizados por Hofstede (1991) e Tanure (2005), estão presentes na Cultura Comercial do Grupo Algar em apenas alguns dos critérios propostos pelo IBIE (2008) para caracterizar uma cultura empreendedora (Quadro 6).

O presente estudo centra-se na presença das dimensões culturais nacionais na Cultura Comercial do Grupo Algar que, por sua vez, foi comparada às dimensões da cultura empreendedora do modelo IBIE (2008). A análise evidencia que a Cultura Comercial do Grupo Algar, conforme disseminada nos documentos institucionais, caracteriza-se pela baixa distância do poder e pela feminilidade, o que permite associá-la ao conceito de Corporate Entrepreneurship, no que concerne a essas duas dimensões. Porém, ao compará-la com as dimensões da cultura nacional, encontram-se divergências dos resultados encontrados por Tanure (2005), que revelam uma alta distância do poder e a alta masculinidade presentes na cultura nacional.

Quanto às outras dimensões, conforme o estudo de Tanure (2005), a cultura nacional é caracterizada pelo coletivismo e pela orientação para o longo prazo. Nessas dimensões, o comportamento da empresa e o processo de trabalho, utilizados para identificar a cultura empreendedora, evidenciouse a presença do coletivismo e da orientação para o longo prazo; o que não 
aconteceu quanto à recompensa para a inovação, que indica uma orientação para a competição, portanto, para o individualismo, e, consequentemente, o predomínio de recompensas financeiras sobre as sociais sinalizam para uma orientação de curto prazo.

O Corporate Entrepreneurship caracteriza-se por uma baixa aversão à incerteza, visto que a inovação exige uma propensão ao risco. Nos documentos analisados não foram encontrados indícios quanto ao processo de trabalho e à recompensa à inovação. A disseminação da Cultura Comercial do Grupo Algar não sinaliza para a existência de ações específicas que façam do erro a base para a aprendizagem e que esclareçam aos funcionários quanto a se sentirem confortáveis com a mudança, ainda que se promovam cursos,

\begin{tabular}{|c|c|c|c|}
\hline \multirow{2}{*}{$\begin{array}{l}\text { Dimensões da cultura } \\
\text { nacional que caracte- } \\
\text { rizam a cultura } \\
\text { empreendedora }\end{array}$} & \multicolumn{3}{|c|}{ Cultura Comercial } \\
\hline & $\begin{array}{c}\text { Comportamento da } \\
\text { empresa }\end{array}$ & $\begin{array}{l}\text { Processo de } \\
\text { trabalho }\end{array}$ & $\begin{array}{l}\text { Recompensa à } \\
\text { Inovação }\end{array}$ \\
\hline $\begin{array}{l}\text { Baixa distância do } \\
\text { poder }\end{array}$ & $\begin{array}{c}\text { Baixa } \\
\text { Transparência e } \\
\text { verdade } \\
\text { Construída } \\
\text { socialmente }\end{array}$ & $\begin{array}{c}\text { Baixa } \\
\text { Comunidade } \\
\text { organizacional forte }\end{array}$ & $\begin{array}{l}\text { Baixa } \\
\text { Critérios são claros }\end{array}$ \\
\hline $\begin{array}{c}\text { Predomínio } \\
\text { da feminilidade } \\
\text { em relação à } \\
\text { masculinidade }\end{array}$ & $\begin{array}{c}\text { Feminina } \\
\text { Alta qualidade de vida } \\
\text { no trabalho }\end{array}$ & $\begin{array}{c}\text { Feminina } \\
\text { Poder de decisão dos } \\
\text { grupos }\end{array}$ & $\begin{array}{c}\text { Feminina } \\
\text { Apoio aos } \\
\text { intraempreendedores }\end{array}$ \\
\hline $\begin{array}{l}\text { Predomínio } \\
\text { do coletivismo } \\
\text { em relação ao } \\
\text { individualismo }\end{array}$ & $\begin{array}{c}\text { Coletivismo } \\
\text { Considera pequenas } \\
\text { iniciativas }\end{array}$ & $\begin{array}{l}\text { Coletivismo } \\
\text { Repasse de responsa- } \\
\text { bilidade e atribuições }\end{array}$ & $\begin{array}{l}\text { Individualismo } \\
\text { Estímulo à } \\
\text { competição }\end{array}$ \\
\hline $\begin{array}{c}\text { Baixa aversão à } \\
\text { incerteza }\end{array}$ & $\begin{array}{l}\text { Baixa } \\
\text { Treinamento e desen- } \\
\text { volvimento contínuo }\end{array}$ & $\begin{array}{l}\text { Não identificado } \\
\text { Conforto com as } \\
\text { mudanças }\end{array}$ & $\begin{array}{l}\text { Não identificado } \\
\text { Erros e fracassos = } \\
\text { base para a aprendi- } \\
\text { zagem }\end{array}$ \\
\hline $\begin{array}{l}\text { Predomínio da } \\
\text { orientação ao } \\
\text { longo prazo }\end{array}$ & $\begin{array}{c}\text { Longo Prazo } \\
\text { Foco nos stakeholders }\end{array}$ & $\begin{array}{l}\text { Longo prazo } \\
\text { Foco no planejamento }\end{array}$ & $\begin{array}{c}\text { Curto prazo } \\
\text { Recompensas } \\
\text { financeiras (predomí- } \\
\text { nio) e sociais }\end{array}$ \\
\hline
\end{tabular}

Quadro 6: Dimensões da Cultura Nacional e da Cultura Comercial da Algar.

Fonte: Adaptado pelos autores a partir de Hofstede (1991) e IBIE (2008). 
treinamentos e capacitações voltadas para a flexibilidade. Nesse sentido é relevante retomar a opinião de autores (DRUCKER, 2005; DOH; PEARCE II, 2004) quanto ao desafio do Corporate Entrepreneurship em criar ou desenvolver uma atmosfera propícia dentro das fronteiras da organização capaz de explorar as descontinuidades geradas pelas incertezas e mudanças próprias do ambiente no qual as organizações estão inseridas.

O estudo de Tanure (2005) aponta para a presença de baixa aversão à incerteza na cultura nacional, diferente dos resultados encontrados por Hofstede (1984). Quanto ao comportamento da empresa, evidencia-se a convergência com Tanure (2005), ou seja, a baixa aversão à incerteza decorrente do modo como a empresa comporta-se em relação à preparação de seus funcionários para o desenvolvimento de múltiplas competências e habilidades.

\section{Considerações Finais}

O conceito de Corporate Entrepreneurship, bem como sua relação com a cultura nacional, é de grande importância para os estudos de empreendedorismo, visto que acrescenta uma dimensão necessária no atual contexto de negócios. As discussões sobre empreendedorismo cresceram nas últimas décadas e muitas vertentes, embora não tenham sido foco deste estudo, contribuem para enriquecer e ajudam a elucidar as questões ensejadas no campo.

As questões de pesquisa inicialmente propostas foram respondidas. Primeiro, tomando como ponto de partida as combinações entre as dimensões culturais nacionais e as dimensões da cultura empreendedora, identificaram-se as características da cultura empreendedora do IBIE (2008) presentes na Cultura Comercial do Grupo analisado. Em seguida, procedeu-se a sua análise visando identificar a presença das dimensões da cultura nacional, o que não se confirmou.

Dentre as contribuições deste estudo, destaca-se, como principal contribuição às organizações de um modo geral e à empresa pesquisada, em particular, o fato de enfatizar a importância de considerar as dimensões da cultura nacional, que desempenha papel fundamental no comportamento dos membros da organização. Outra contribuição foi evidenciar que a Cultura Comercial do Grupo Algar é, potencialmente, capaz de estimular os funcionários a inovar, seja criando novos produtos ou novas formas de organizar. 
A despeito das limitações inerentes à abordagem interpretativo-simbólica, os resultados do presente estudo delineiam algumas sugestões para futuras pesquisas vinculadas ao Corporate Entrepreneurship: (a) a investigação de dimensões culturais regionais, dada a dimensão geográfica do país, poderá trazer à tona outras evidências; (b) a introdução de ações que tornem claro como o erro pode ser utilizado como base para a aprendizagem, de forma a diminuir o grau de aversão à incerteza; (c) pesquisas que privilegiem a cultura organizacional como socialmente construída pelos membros organizacionais, antes que uma relação de elementos, atributos e regras determinadas pela alta direção.

Espera-se, com este trabalho, contribuir para o campo da Administração, em geral, e, em particular, para as empresas vislumbrarem formas de estimular seus funcionários ao desenvolvimento de novos negócios e novos produtos.

\title{
Corporate Entrepreneurship: the presence of the dimensions of national culture in Algar's Business Culture
}

\begin{abstract}
This study approach the Corporate Entrepreneurship, expression that refers as the companie's capability to stimulate initiatives of its employees in such a way that these may proposing new ideas, new businesses and new processes or services. The organizational culture, defined by the collective character and the elements that constitute, is a phenomenon passive of sociocultural and historical influences, what implies considerations about the existence of a national component. The paper analyzes the Commercial Culture of Group Algar at the light of the concept of Corporate Entrepreneurship, with the objective to identify the presence of the dimensions of national culture. The research documental was used in Group's documents with the purpose to spread a concept of Commercial Culture. The results of the research point to the convergence between the concept of Commercial Culture and Entrepreneurial Culture; however, the same does not occur when it deals with the dimensions of national culture.
\end{abstract}

Key-words: Organizational culture. Intrapreneurship. Innovation. 
Cíntia Rodrigues de Oliveira Medeiros • Rodrigo Miranda • Alirio Severo Nogueira Jr.

\section{Referências}

BARDIN, L. Análise de conteúdo. Lisboa: Edições 70, 1979.

BARNEY, J. Organization culture: can it be a source of sustained competitive advantage? Academy of Management Review, California, v. 11, p. 656-65, 1986.

BIGGADIKE, R. The Risky Business of Diversification. Harvard Business Review, Boston, v. 57, n. 3, p. 103-111, 1979.

BIGNÉ, E. et al. Percepción de La Responsabilidad Social Corporativa: un análisis cross-cultural. Universia Business Review, Madrid, n. 5, p. 14-27, 2005.

CASTELLS, M. A sociedade em rede. 4. ed. São Paulo: Paz e Terra, 2000. (V. I)

CHESBROUGH, H. W. Making Sense of Corporate Venturing Capital. Harvard Business Review, Boston, v. 80, n. 3, p. 90-97, 2002.

CLAVER, E. et al. Organizational culture for innovation and new techonological behavior. The Journal of High Technology Management Research, Oxford, v. 9, n. 1, p. 55-68, 1998.

DOH, J. P.; PEARCE II, J. A. Corporate Entrepreneuship and Real Options in Transitional Policy Enviroments: Theory Development. Journal of

Management Studies, London, v. 41, n. 4, p. 645-664, 2004.

DRUCKER, P. F. Inovação e espírito empreendedor. São Paulo: Pioneira Thomson Learning, 2005

EKVALL, G.; ARVONEN, J. Change-centered leadership: an extension of the two-dimensional model. Journal of Management, London, v. 27, n. 1, p. 1726, 1991.

FARREL, L. C. Entrepreneurship: fundamentos das organizações empreendedoras. São Paulo: Atlas, 1993.

FILLION, L. J. Empreendedorismo: empreendedores e proprietários-gerentes de pequenos negócios. RAUSP, São Paulo, v. 34, n. 2, p. 5-28, abr.jun. 1999.

HAMEL, G. Inovação Sistêmica e Radical! HSM Management, São Paulo, n. 36, p. 73-78, jan./fev. 2003. 
Corporate Entrepreneurship: a presença das dimensões da cultura nacional na cultura comercial do Grupo Algar

HATCH, M. J. The dynamics of organizational culture. The Academy of Management Review, California, v. 18, n. 4, p. 657-693, 1993.

HOFSTEDE, G. Culture's consequences international differences in work-related values. Beverly Hills, CA: Sage, 1984

Cultural constraints in management theories. Academy of

Management Executive, Califórnia, v. 7, n. 1, p. 81-94, 1993.

Cultural dimensions. Disponível em: <http://www.geert-

hofstede.com>. Acesso em: 10. fev. 2007.

HOFSTEDE, G. J.; PEDERSON, P.B.; HOFSTEDE, G. Exploring Culture: Exercises, Stories and Synthetic Cultures. Yarmounth, Ma: Intercultural Press, 2002.

IBIE. Intraempreeendedorismo. Disponível em: <http://www.ibis.org.br $>$. Acesso em: 18. abr. 2008

JASSAWALLA, A. R.; SASHITTAL, H. C. Cultures that support product innovation processes. Academy of Management Executive, California, $v$. 16, n. 3, p. 42-53, 2002.

KHAZANCHI, S.; LEWIS, M. W.; BOYER, K. K. Innovation-supportive culture: the impacto $f$ organizational values on process innovation. Journal of Operations Management, New York, v. 25, p. 871-884, 2007.

LEE, S. M.; PETERSON, S. J. Culture, Entrepreneurial Orientation, and Global Competitiveness. Journal of World Business, New York, v. 35, n. 4, p. 401416, 2000.

LINDELL, M.; ARVONEN, J. The Nordic Management Style in a European Context. International studies of management \& organization, London, v. 26, n. 3, p. 73-91, 1997.

MARTIN, J. Organizational Culture. London: Sage Publications, 2002.

MEARNS, K.; YULE, S. The role of national culture in determining safety performance: Challenges for the global oil and gas industry. Safety Science. In Press. 2008. 
Cíntia Rodrigues de Oliveira Medeiros • Rodrigo Miranda • Alirio Severo Nogueira Jr.

MORGAN, G. Paradigms, Metaphors, and Puzzle Solving in Organization Theory. Administrative Science Quarterly, Ithaca, v. 25, n. 4, p. 605-628, 1980.

MORSE, C. W. The delusion of intrapreneurship. Long Range Planning, London, v. 19, n. 6, p. 92-95, 1986.

NELSON, R. R.; WINTER, S. G. An evolutionary theory of economic change. Cambridge, Massachusetts: Harvard University Press, 1982.

OJASALO, J. Management of innovation networks: a case study of different approaches. European Journal of Innovation Management, London, v. 11, n. 1, p. 51-86, 2008.

PETERS, T. J.; WATERMAN, R. H. Vencendo a crise. São Paulo: Harbra, 1986.

PINCHOT, G. Innovation Through Intrapreneuring. Research Management, Washington, v. 30, n. 2, 1987.

SCHUMPEPETER, Joseph A. The creative response in economic history.

Journal of Economic History, Cambridge University Press, v. II, n. 2, p. 149159, nov. 1947.

SHAW, E.; O'LOUGHLIN, A.; McFADZEAN, E. Corporate entrepreneurship and innovation part 2. European Journal of Innovation Management, London, v. 8, n. 4, p. 393-408, 2005.

TANURE, B. Gestão à brasileira: uma comparação entre América Latina, Estados Unidos, Europa e Ásia. 2. ed. São Paulo: Atlas, 2005.

VON HIPPEL, E. The Dominant Role of the User in Semiconductor and Eletronic Subassembly Process Innovation. IEE Transactions of Engineering Management, v. 24, n. 2, p. 60-71, 1977. 